\title{
Buckling Behaviour of Protein Microtubules
}

\author{
Ali Farajpour ${ }^{1}$, Mergen H Ghayesh ${ }^{1 *}$, Hamed Farokhi ${ }^{2}$, Alireza Gholipour ${ }^{1}$ and Harry J Carpenter ${ }^{1}$ \\ ${ }^{1}$ School of Mechanical Engineering, University of Adelaide, Australia
}

${ }^{2}$ Department of Mechanical and Construction Engineering, North Umbria University, UK

*Corresponding author: Mergen H Ghayesh, School of Mechanical Engineering, University of Adelaide, Australia

\begin{abstract}
Protein microtubules take part in several cellular activities including mitosis, cell movement and migration. During these cellular activities, they can be subject to various types of external loading and pressure. In this study, the bucking of protein microtubules obtained via scale-dependent continuum models are investigated. Several continuum-based formulations, which have been proposed for the buckling of protein microtubules, are reviewed briefly. Finally, the effects of surface elastic properties on the growth rate of buckling in protein microtubules are studied.
\end{abstract}

Keywords: Protein microtubules; Buckling; Axial loading; Size effects

\section{Introduction}

Size effects have a crucial role to play in the statics and dynamics of various ultra-small structures [1-6]. On the other hand, the mechanics of nanostructures [7-14] and microstructures [15-26] is of high importance due to their applications in different nanomechanical and micromechanical systems such as Nano sensors and nanoactuators. Therefore, developing sizedependent mathematical frameworks for analyzing the statics and dynamics of both nanostructures and microstructures would provide a useful tool in nanoengineering and microengineering. Protein microtubules are one of the most important parts of living cells, which participate in many processes inside cells $[27,28]$. For instance, in the process of mitosis, microtubules help chromosomes to separate and migrate into two opposite positions. In addition, these filaments provide a reliable pathway for protein transportation inside cells. In these processes, microtubules are likely to be subject to various loads such as axial compression. In this study, the buckling instability of protein microtubules under axial compressive loads is investigated. Different size-dependent models of these small-scale structures are also reviewed.

\section{Buckling of Microtubules}

Let us consider a single microtubule of length $\mathrm{L}$, inner radius $\mathrm{Ri}$ and outer radius Ro. The microtubule has a hollow cylindrical geometry and consists of $\alpha$ and $\beta$ tubulins, as shown in (Figure 1). It has been proven that size influences have a significant impact on the mechanica0000000l behavior at small-scales [29-36]. Since the inner and outer radii of microtubules are of several nanometers, the nonlocal theory is mostly used to describe size influences. The nonlocal theory is an elasticity-based theoretical tool, which was first utilized by Peddieson et al. [37] for the deformation of nanostructures. According to this theory, we have the following differential equation for the constitutive response of microtubules.

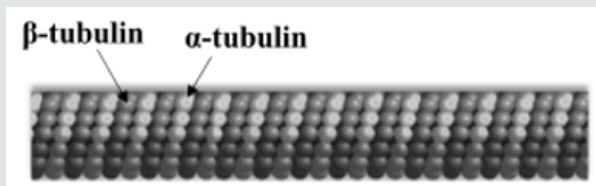

Protein microtubule

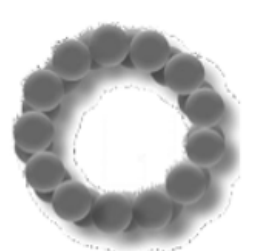

Cross-sectional area

Figure 1: The structure of a protein microtubule. 


$$
\sigma-\mu_{n l}-\nabla^{2} \sigma=C: \varepsilon
$$

Where

$$
\mu_{n l}=\left(e_{0} l_{c}\right)^{2},
$$

In which $\sigma, \mathrm{C}$ and $\varepsilon$ are, respectively, the stress, elasticity and strain tensors; moreover, $\nabla^{2}$ and $\mathrm{e}_{0} \mathrm{l}_{\mathrm{c}}$ stand for the Laplace operator and nonlocal constant, respectively; also, $\mathrm{l}_{\mathrm{c}}$ and $\mathrm{e}_{0}$ are symbols, which are used for calibrating the model and incorporating the effects of the internal configuration of the structure [38,39]. In addition to nonlocal effects, surface influences have a crucial role to play in the mechanics of ultra small structures such as microtubules. At nanoscales, surface influences become important since the ratio of the surface energy to its bulk counterpart substantially increases. For the microtubule, there are two different surface layers (i.e. outer and inner surface layers). To incorporate surface influences, the following equations can be utilized $[40,41]$.

$$
\sigma_{\text {sur }=} \tau_{\text {sur }}+C_{\text {sur }} \varepsilon_{\text {sur }}
$$

Where

$$
\lambda_{\text {sur }}=\left[\Lambda+\frac{\partial \Lambda}{\partial \varepsilon_{s u r}}\right]_{\varepsilon_{s u r}=0}
$$

Here "sur" is employed to indicate "surface". $\lambda_{\text {sur }}$ is the residual stress in surface layers [42], and $\wedge$ represents the microtubule surface energy density. Figure 2 depicts the dimensionless growth rate of buckling in protein microtubules [43] subject to axial compression. Calculations are conducted for various surface elastic constants [40]. The horizontal axis of the figure denotes the instability wave number. It is concluded that the growth rate of buckling in microtubules decreases when the elastic constant of surface layers increases. This is because of the fact that the surface elastic constant is associated with an increase in the microtubule stiffness.

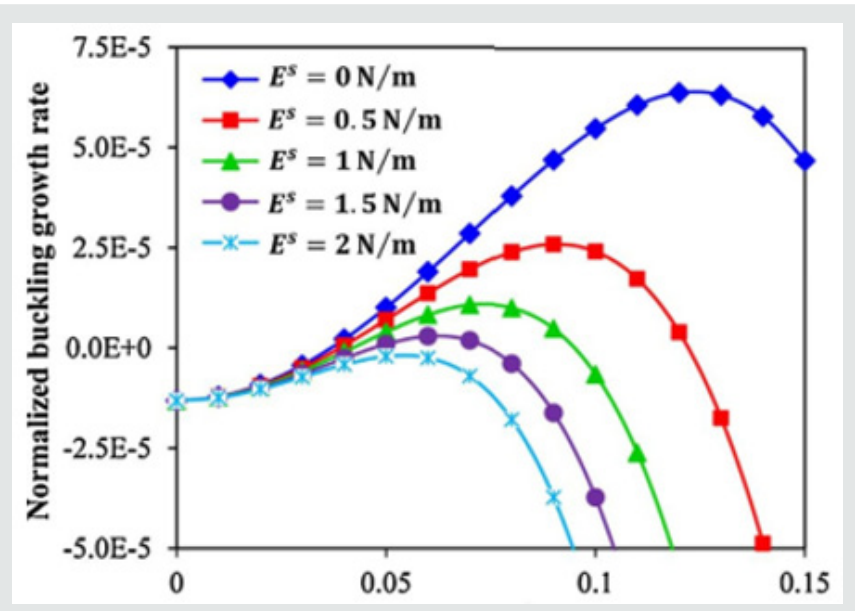

Figure 2: Buckling behaviour of microtubules for different surface elastic constants [40].

\section{Conclusion}

The buckling instability of microtubules in human cells has been investigated via scale-dependent theoretical models. Two main scale-dependent theories for the statics and dynamics of microtubules (i.e. surface and nonlocal theories of elasticity) were reviewed briefly. Finally, the influences of buckling wave number and surface elastic constant on the buckling behaviour were studied. It was concluded that higher surface elastic constants substantially reduce the growth rate of buckling in the protein microtubule.

\section{References}

1. M Şimşek (2016) Nonlinear free vibration of a functionally graded nanobeam using nonlocal strain gradient theory and a novel Hamiltonian approach. International Journal of Engineering Science 105: 12-27.

2. B Akgöz, Ö Civalek (2011) Application of strain gradient elasticity theory for buckling analysis of protein microtubules. Current Applied Physics 11(5): 1133-1138.

3. H Farokhi, M H Ghayesh, Nonlinear mechanics of electrically actuated microplates, International Journal of Engineering Science, 123 (2018) 197-213.

4. MH Ghayesh (2018) Functionally graded microbeams: Simultaneous presence of imperfection and viscoelasticity. International Journal of Mechanical Sciences 140: 339-350.
5. MH Ghayesh, H Farokhi, G Alici (2015) Size-dependent electro elasto mechanics of MEMS with initially curved deformable electrodes. International Journal of Mechanical Sciences 103: 247-264.

6. H Farokhi, MH Ghayesh (2016) Size dependent behaviour of electrically actuated microcantilever based MEMS. International Journal of Mechanics and Materials in Design 12(3): 301-315.

7. A Farajpour, MH Ghayesh, H Farokhi (2018) A review on the mechanics of nanostructures. International Journal of Engineering Science 133:231263.

8. A Farajpour, MH Ghayesh, H Farokhi (2019) Large amplitude coupled scale dependent behaviour of geometrically imperfect NSGT nanotubes. International Journal of Mechanical Sciences 150: 510-525.

9. MH Ghayesh, A Farajpour (2018) Nonlinear mechanics of nanoscale tubes via nonlocal strain gradient theory. International Journal of Engineering Science 129: 84-95.

10. A Farajpour, A Rastgoo, M Farajpour (2017) Nonlinear buckling analysis of magneto electro elastic CNT-MT hybrid nanoshells based on the nonlocal continuum mechanics. Composite Structures 180: 179-191.

11. MR Farajpour, A Shahidi, A Farajpour (2018) Resonant frequency tuning of nanobeams by piezoelectric nanowires under thermo electromagnetic field: a theoretical study. Micro \& Nano Letters 13(11): 1627- 1632.

12. SR Asemi, A Farajpour (2014) Vibration characteristics of double piezoelectric nanoplate systems, Micro \& Nano Letters 9(4): 280-285. 
13. M Farajpour, A Shahidi, A Farajpour (2018) A nonlocal continuum mode for the biaxial buckling analysis of composite nanoplates with shape memory alloy nanowires. Materials Research Express 5: 035026.

14. M Farajpour, A Shahidi, F Tabatabai Nasab, A Farajpour (2018) Vibration of initially stressed carbon nanotubes under magneto thermal environment for nanoparticle delivery via higher order nonlocal strain gradient theory. The European Physical Journal Plus 133: 219.

15. H Farokhi, MH Ghayesh (2017) Nonlinear resonant response of imperfect extensible Timoshenko microbeams. International Journal of Mechanics and Materials in Design 13(1): 43-55.

16. MH Ghayesh, H Farokhi (2017) Parametric vibrations of imperfect Timoshenko microbeams. Microsystem Technologies 23(10): $4917-$ 4929.

17. MH Ghayesh (2019) Viscoelastic dynamics of axially FG microbeams: International Journal of Engineering Science 135: 75-85.

18. H Farokhi, MH Ghayesh, B Kosasih, P Akaber (2016) On the nonlinear resonant dynamics of Timoshenko microbeams: effects of axial load and geometric imperfection. Meccanica 51(1): 155-169.

19. MH Ghayesh (2019) Viscoelastically coupled dynamics of FG Timoshenko microbeams. Microsystem Technologies 25(2): 651-663.

20. H Farokhi, MH Ghayesh, S Hussain (2016) Dynamic stability in parametric resonance of axially excited Timoshenko microbeams. Meccanica 51(10): 2459-2472.

21. MH Ghayesh, A Farajpour (2019) A review on the mechanics of functionally graded nanoscale and microscale structures International Journal of Engineering Science 137: 8-36.

22. MH Ghayesh, A Farajpour (2018) Vibrations of shear deformable FG viscoelastic microbeams. Microsystem Technologies 25(4): 1387-1400.

23. H Farokhi, MH Ghayesh (2018) Supercritical nonlinear parametric dynamics of Timoshenko microbeams. Communications in Nonlinear Science and Numerical Simulation 59: 592-605.

24. MH Ghayesh, H Farokhi, S Hussain (2016) Viscoelastically coupled size dependent dynamics of microbeams. International Journal of Engineering Science 109: 243-255.

25. MH Ghayesh, H Farokhi (2017) Nonlinear mechanics of doubly curved shallow microshells. International Journal of Engineering Science 119: 288-304.

26. K Rashvand, G Rezazadeh, H Mobki, M H Ghayesh (2013) On the size dependent behavior of a capacitive circular micro plate considering the variable length scale parameter. International Journal of Mechanical Sciences 77: 333-342.

27. KE Sawin, K LeGuellec, M Philippe, T J Mitchison, (1992) Mitotic spindle organization by a plus end directed microtubule motor. Nature 359(6395): 540-543.

28. MA Jordan, L Wilson (2004) Microtubules as a target for anticancer drugs. Nature Reviews Cancer 4: 253-265.
29. A Farajpour, MH Ghayesh, H Farokhi (2019) A coupled nonlinear continuum model for bifurcation behaviour of fluid conveying nanotubes incorporating internal energy loss. Microfluidics and Nanofluidics 23:34.

30. H Farokhi, MH Ghayesh, A Gholipour, S Hussain (2018) Modal interactions and energy transfers in large amplitude vibrations of functionally graded microcantilevers. Journal of Vibration and Control 24(17): 3882-3893.

31. A Farajpour, H Farokhi, MH Ghayesh (2019) Chaotic motion analysis of fluid conveying viscoelastic nanotubes European Journal of Mechanics A/Solids 74: 281-296.

32. MH Ghayesh, H Farokhi, A Farajpour (2019) Global dynamics of fluid conveying nanotubes. International Journal of Engineering Science 135: 37-57.

33. A Farajpour, H Farokhi, MH Ghayesh, S Hussain (2018) Nonlinear mechanics of nanotubes conveying fluid. International Journal of Engineering Science 133: 132-143.

34. A Farajpour, MH Ghayesh, H Farokhi (2019) Application of nanotubes in conveying nanofluid: a bifurcation analysis with consideration of internal energy loss and geometrical imperfection. Microsystem Technologies PP: 1-15.

35. MH Ghayesh, H Farokhi (2018) On the viscoelastic dynamics of fluid conveying microtubes. International Journal of Engineering Science 127: 186-200.

36. A Farajpour, A Rastgoo (2017) Influence of carbon nanotubes on the buckling of microtubule bundles in viscoelastic cytoplasm using nonlocal strain gradient theory. Results in physics 7: 1367-1375.

37. J Peddieson, GR Buchanan, RP McNitt (2003) Application of nonlocal continuum models to nanotechnology. International Journal of Engineering Science 41(3-5): 305-312.

38. Y Gao, FM Lei (2009) Small scale effects on the mechanical behaviors of protein microtubules based on the nonlocal elasticity theory. Biochemical and Biophysical Research Communications 387(3): 467471.

39. J Wang, Y Gao (2016) Nonlocal orthotropic shell model applied on wave propagation in microtubules. Applied Mathematical Modelling 40(1112): $5731-5744$.

40. A Farajpour, A Rastgoo, M Mohammadi (2014) Surface effects on the mechanical characteristics of microtubule networks in living cells. Mechanics Research Communications 57: 18-26.

41. RC Cammarata (1994) Surface and interface stress effects in thin films Progress in surface science 46: 1-38.

42. B Farshi, A Assadi, A Alinia Ziazi (2010) Frequency analysis of nanotubes with consideration of surface effects, Applied Physics Letters 96(9): 093105 .

43. T Li (2008) A mechanics model of microtubule buckling in living cells. Journal of biomechanics 41(8): 1722-1729.

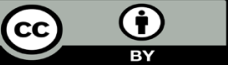

This work is licensed under Creative Commons Attribution 4.0 License

To Submit Your Article Click Here: Submit Article

DOI: 10.32474/ARME.2019.02.000129

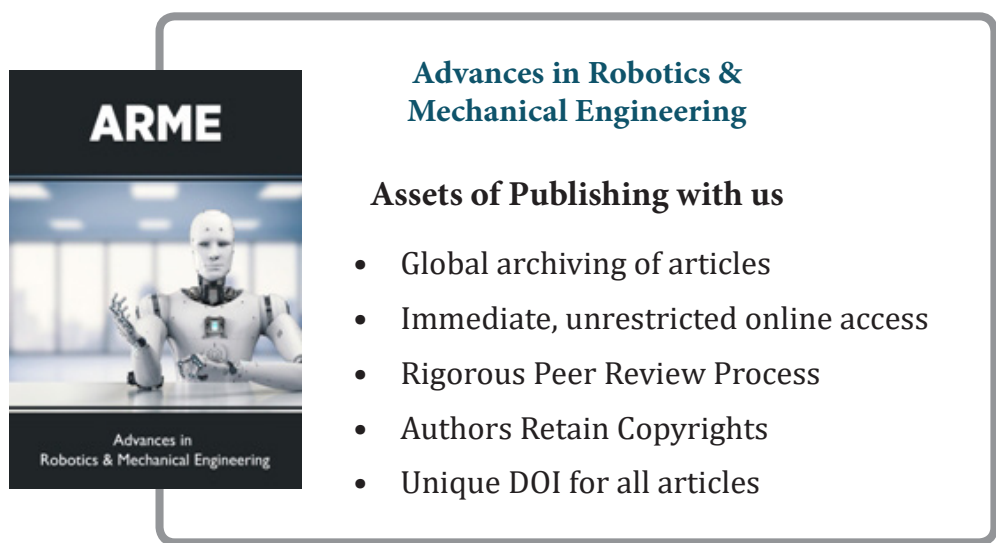

